\title{
Intermittent haemodialysis and sustained low-efficiency dialysis (SLED) for acute theophylline toxicity
}

\author{
Julia Fisher • Andis Graudins
}

Published online: 21 March 2015

(C) American College of Medical Toxicology 2015

\begin{abstract}
Introduction Theophylline overdose can result in significant cardiovascular and neurologic toxicity and is potentially fatal. Clearance of theophylline can be enhanced by the administration of multiple-dose activated charcoal (MDAC) and extracorporeal elimination techniques. We report a case of severe theophylline toxicity initially treated with MDAC and intermittent haemodialysis. Subsequent to this, sustained lowefficiency dialysis (SLED) was undertaken. This is a prolonged renal replacement therapy that uses blood and dialysate flow rates between those of intermittent haemodialysis and continuous renal replacement therapy.

Case report A 61-year-old man presented following ingestion of $24 \mathrm{~g}$ of theophylline SR (300 mg/kg), $240 \mathrm{mg}$ of diazepam and $2 \mathrm{~g}$ of gabapentin. He required intubation and developed a supraventricular tachycardia treated with esmolol, but suffered no seizures. Serum theophylline concentration peaked at $636 \mu \mathrm{mol} / \mathrm{L}(55-110)$ at $9.5 \mathrm{~h}$ post-ingestion. Intermittent haemodialysis was performed for $4 \mathrm{~h}$ and resulted in a theophylline extraction ratio of 0.57 with elimination half-life of $2.3 \mathrm{~h}$. SLED was subsequently performed on two occasions for $7 \mathrm{~h}$. Theophylline extraction ratio ranged from 0.46 (halflife $5.3 \mathrm{~h}$ during the first cycle) to 0.61 (half-life $10.6 \mathrm{~h}$ during the second cycle). After cessation of SLED, elimination halflife was $26 \mathrm{~h}$. The patient made an uneventful recovery. Discussion Intermittent haemodialysis is the current recommended extracorporeal technique for enhancing theophylline
\end{abstract}

J. Fisher $(\bowtie) \cdot$ A. Graudins

Department of Emergency Medicine, Monash Health,

Victoria, Australia

e-mail: julia.fisher@monashhealth.org

A. Graudins

Southern Clinical School, Faculty of Medicine Nursing and Health

Sciences, Monash University, Clayton, Victoria, Australia elimination in the absence of charcoal haemoperfusion. However, SLED produced similar apparent extraction ratios with longer associated elimination half-life for theophylline than for intermittent haemodialysis. SLED is undertaken by intensive care unit (ICU) staff and may be a useful extracorporeal elimination technique in cases where access to intermittent haemodialysis, requiring specialist dialysis nursing staff, is limited or may be delayed.

Keywords Theophylline · Overdose · Haemodialysis · Sustained low-efficiency dialysis $\cdot$ Poisoning

\section{Introduction}

Theophylline has traditionally been used to treat asthma and chronic obstructive pulmonary disease; however, other more effective bronchodilator therapies have replaced it in more recent years. Nonetheless, theophylline has potential for significant morbidity and mortality following overdose. It is one of a small number of drugs where elimination may be enhanced by exogenous means and toxicity mitigated by rapid reduction in blood drug concentration. Administration of enteric multiple-dose activated charcoal (MDAC) reduces elimination half-life $[1,2]$. In addition, extracorporeal elimination techniques also increase theophylline clearance. There are limited reports on the use of sustained low-efficiency haemodialysis (SLED) in the treatment of poisoning, and no reports of its use in theophylline poisoning. We report a case of severe theophylline toxicity treated initially with MDAC and intermittent haemodialysis, followed by SLED therapy. 


\section{Case Report}

A 61-year-old man, with a history of depression, asthma, multiple myeloma and chronic back pain presented following intentional ingestion of $24 \mathrm{~g}$ of theophylline SR (Nuelin SR, 250-mg tablets, iNova Pharmaceuticals, Chatswood, NSW, Australia) $(300 \mathrm{mg} / \mathrm{kg}), 240 \mathrm{mg}$ of diazepam and $2 \mathrm{~g}$ of gabapentin. On arrival to the emergency department $2 \mathrm{~h}$ post-ingestion, he was alert and asymptomatic with a blood pressure (BP) of 130/80 mmHg, heart rate (HR) $103 \mathrm{bpm}$ and temperature $36.3^{\circ} \mathrm{C}$. Physical examination was normal. Initial ECG revealed a narrow complex sinus tachycardia at $104 \mathrm{bpm}$ and venous blood gas showed $\mathrm{pH} 7.44$ (7.35-7.45), $\mathrm{pCO}_{2}$ $36 \mathrm{mmHg}(41-51), \mathrm{HCO}_{3} 24 \mathrm{mmol} / \mathrm{L}(21-30)$, lactate $3.1 \mathrm{mmol} / \mathrm{L}(0.5-2.0)$ and glucose $5.7 \mathrm{mmol} / \mathrm{L}(3-10)$.

Blood taken $2 \mathrm{~h}$ post-ingestion revealed serum theophylline concentration of $233 \mu \mathrm{mol} / \mathrm{L}$ (55-110), paracetamol concentration of $<66 \mu \mathrm{mol} / \mathrm{L}$ and ethanol $<1 \mathrm{mmol} / \mathrm{L}$. Serum potassium was $3.7 \mathrm{mmol} / \mathrm{L}(3.5-5.0)$ and magnesium $0.71 \mathrm{mmol} / \mathrm{L}(0.74$ 1.03). Other serum electrolytes and renal function were normal.

Fifty grammes of oral activated charcoal was administered $2.5 \mathrm{~h}$ post-ingestion. This was followed by the commencement of whole bowel irrigation with polyethylene glycolelectrolyte solution (ColonLYTELY, Dendy Pharmaceuticals, Australia) at a rate of $1 \mathrm{~L} / \mathrm{h}$. Over the following $2 \mathrm{~h}$, he developed a tremor and a mild tachycardia (102-114 bpm), but remained alert and calm. The patient was referred to the intensive care unit (ICU) for haemodialysis.

On arrival to the ICU $4.5 \mathrm{~h}$ post-ingestion, agitation and intractable vomiting developed, necessitating endotracheal intubation. A supraventricular tachycardia (HR $190 \mathrm{bpm}$ ) and hypotension (systolic BP $70 \mathrm{mmHg}$ ) developed immediately post-intubation. This was treated with intravenous doses of metaraminol to a total of $10 \mathrm{mg}$ and intermittent doses of esmolol to a total of $40 \mathrm{mg}$ over $30 \mathrm{~min}$ resulting in reversion to sinus rhythm and HR $110 \mathrm{bpm}$ with BP 130/75 mmHg. An esmolol infusion was commenced and adjusted to maintain HR 90 to $110 \mathrm{bpm}$.

Five hours post-ingestion, serum theophylline concentration was $423 \mu \mathrm{mol} / \mathrm{L}$. This peaked at $636 \mu \mathrm{mol} / \mathrm{L}, 9.5 \mathrm{~h}$ postingestion.

Intermittent haemodialysis was commenced $9.5 \mathrm{~h}$ postingestion (High-Flux FX CorDiax 80 filter, $95 \mathrm{~mL}$, Fresenius Medical Care, Bad Homburg, Germany) with a blood flow rate of $250 \mathrm{~mL} / \mathrm{min}$. The duration of haemodialysis was $4 \mathrm{~h}$. Blood for serum theophylline concentrations was drawn from afferent and efferent lines during dialysis. The blood extraction ratio (ER) of theophylline across the haemodialysis filter was calculated using the formula $\mathrm{ER}=(A-V) / A$, where $A$ and $V$ are the concentrations of theophylline in the blood entering and leaving the filter, respectively. The extraction ratio during intermittent haemodialysis was 0.57 . Serum theophylline concentrations pre- and posthaemodialysis filter are detailed in Table 1.
MDAC was administered (four doses of $25 \mathrm{~g}$ ), while whole bowel irrigation was continued via nasogastric tube at a rate of $1000 \mathrm{~mL} / \mathrm{h}$ for $36 \mathrm{~h}$.

Following haemodialysis, SLED was performed for $7 \mathrm{~h}$ with a blood flow rate of $180 \mathrm{~mL} / \mathrm{min}$ (5008 AV600S filter, $100 \mathrm{~mL}$, Fresenius Medical Care, Bad Homburg, Germany). The extraction ratio during SLED ranged from 0.46 to 0.61 (Table 1). Following the first session of SLED, serum theophylline concentration dropped to $187 \mu \mathrm{mol} / \mathrm{L}$ (see Fig. 1). However, this rebounded to $319 \mu \mathrm{mol} / \mathrm{L} 3 \mathrm{~h}$ later. A further $6 \mathrm{~h}$ of SLED was performed, and serum theophylline concentration fell to $178 \mu \mathrm{mol} / \mathrm{L}$, before the SLED machine malfunctioned. Continuous veno-venous haemodialysis (CVVHD) was then performed for $6 \mathrm{~h}$ (AN69 ST100 hollow fibre filter, $150 \mathrm{~mL}$, Prismaflex, Gambro Lundia, Sweden). Given that the initial MDAC treatment was well tolerated and bowel sounds were present, a second regimen of MDAC (five doses of $10 \mathrm{~g}$ over $8 \mathrm{~h}$ ) was also administered with the CVVHD, to assist in theophylline elimination.

Serum theophylline concentrations are summarized in Fig. 1. Elimination rate constants were calculated, and from those, estimations of elimination half-life and plasma clearance during each session of dialysis were made.

Noradrenaline infusion was commenced $12 \mathrm{~h}$ post-ingestion following an episode of hypotension (BP 75/60 $\mathrm{mmHg}$ ) and titrated to blood pressure $(1-5 \mathrm{mcg} / \mathrm{min})$ until day 2 post-ingestion. Esmolol infusion was ceased after 3 days.

The patient developed ventilator-associated pneumonia, which delayed his extubation to day 5 post-ingestion. He was transferred to a medical ward the following day. He experienced no further arrhythmias and no seizures. A delirium (secondary to pneumonia) resolved by day 10 , and he was subsequently transferred to an inpatient psychiatric ward.

\section{Discussion}

Theophylline stimulates the release of endogenous catecholamines resulting primarily in beta- 2 adrenoceptor stimulation

Table 1 Serum theophylline concentration, extraction ratios and plasma clearance during haemodialysis where $E=(A-V) / A$ and $\mathrm{Cl}=$ blood flow (1-haematocrit $) \times E$

\begin{tabular}{llllll}
\hline Dialysis method & \multicolumn{7}{l}{ Time post-ingestion (h) } \\
\cline { 2 - 6 } & $\begin{array}{l}9.5 \\
\text { Intermittent HD }\end{array}$ & $\begin{array}{l}12.5 \\
\text { SLED }\end{array}$ & 18 & 22 \\
& 636 & 351 & 328 & 243 & 187 \\
\hline $\begin{array}{c}\text { Serum theophylline concentration } \\
\text { pre-filter }(A)(\mu \mathrm{mol} / \mathrm{L})\end{array}$ & 276 & 117 & 178 & 123 & 72 \\
$\begin{array}{c}\text { Serum theophylline concentration } \\
\text { post-filter }(V)(\mu \mathrm{mol} / \mathrm{L})\end{array}$ & 0.57 & 0.67 & 0.46 & 0.49 & 0.61 \\
$\begin{array}{c}\text { Extraction ratio }(E) \\
\text { Plasma clearance }(\mathrm{Cl})(\mathrm{mL} / \mathrm{min})\end{array}$ & 88 & 103 & 53 & 57 & 71 \\
\hline
\end{tabular}




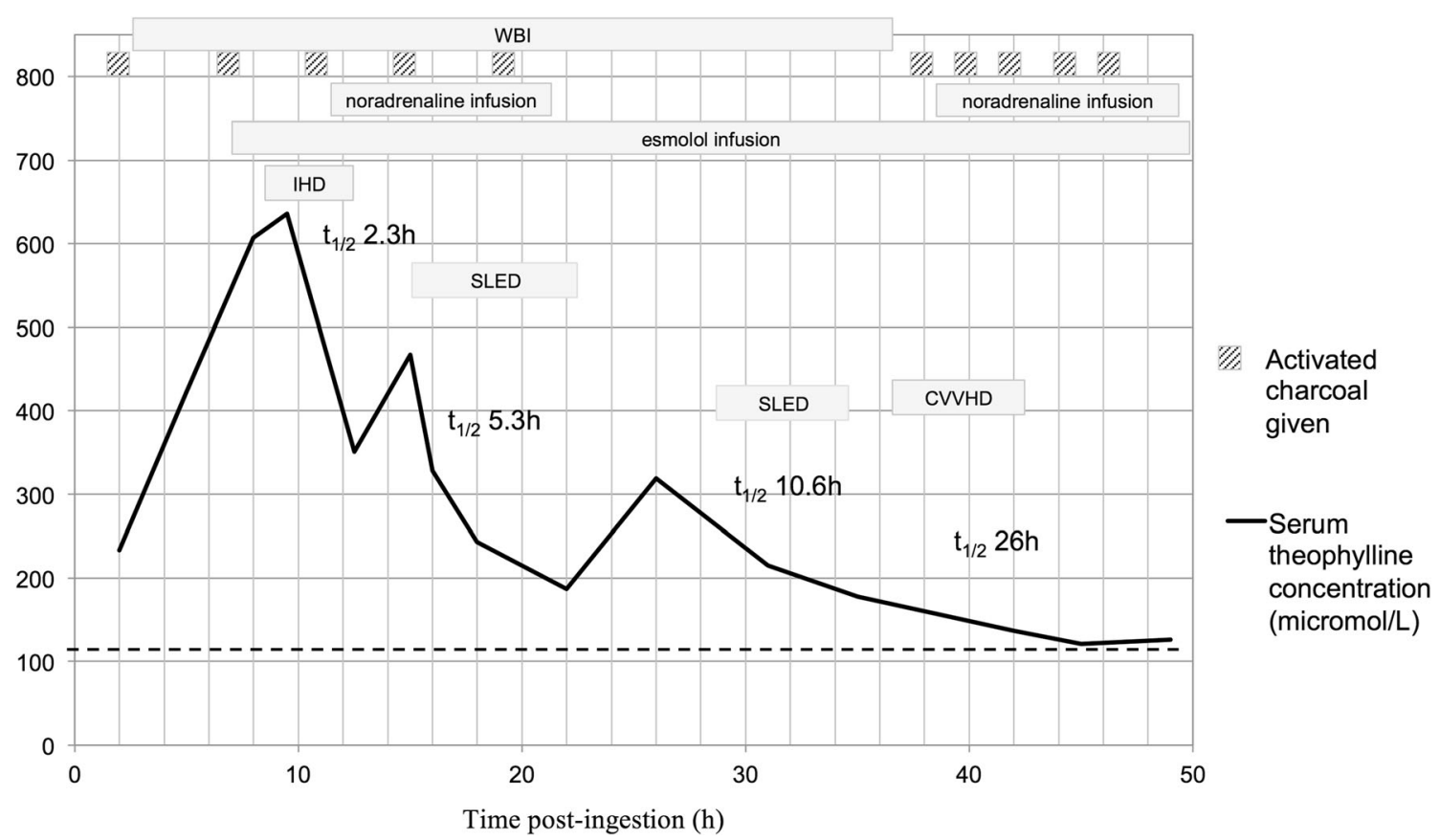

Fig. 1 Summary of serum theophylline concentrations and treatment instituted after theophylline overdose. Solid line represents serum theophylline concentration. Dashed line represents upper therapeutic limit of theophylline concentration

and pulmonary bronchodilation [3]. Theophylline also inhibits phosphodiesterase, increasing intracellular cyclic adenosine monophosphate, adding effects similar to direct adrenergic stimulation. It is an antagonist of adenosine receptors [3] and stimulates the chemoreceptor trigger zone in the brain stem [4]. In overdose, cardiovascular and metabolic effects are primarily the result of excess sympathomimetic stimulation and include sinus, supraventricular and ventricular tachycardia, beta-2 sympathomimetic vasodilation and hypotension as well as hypokalaemia, hypomagnesaemia, hyperglycaemia and lactic acidemia. Neurologic effects include anxiety, tremor and agitation related to sympathomimetic effects and intractable seizures, primarily related to adenosine receptor antagonism. Protracted nausea and vomiting are often present, making GI decontamination difficult to perform.

Our patient presented early post-ingestion. His toxicity gradually progressed, as expected with a sustained-release preparation, over the next 4 to $6 \mathrm{~h}$ and was manifest primarily by cardiovascular signs, including tachycardia and hypotension. He was intubated and sedated early, and significant CNS toxicity and seizures were not observed.

Management of theophylline toxicity is complex and combines targeted supportive measures as well as early gastrointestinal (GI) decontamination and enhanced elimination techniques to mitigate toxicity.

Hypotension may respond to alpha-adrenergic stimulants such as norepinephrine; however, paradoxically, treatment with non-selective beta-receptor antagonists may reverse refractory hypotension and treat tachyarrhythmias caused by excess beta-2 adrenoreceptor stimulation [5]. CNS excitation will require treatment with sedative agents such as benzodiazepines or barbiturates. Our patient received continuous infusions of midazolam, propofol and fentanyl.

When sustained-release preparations are ingested, GI decontamination with single-dose activated charcoal followed by whole bowel irrigation may reduce the absorbed drug load [6]. We instituted both measures on presentation; however, given the ingested amount of theophylline, toxicity progressed in this case.

In cases where serum theophylline concentrations are already elevated and/or clinical toxicity has manifested, enhanced elimination techniques including MDAC and extracorporeal elimination are indicated. Theophylline elimination is increased by the administration of MDAC and has been described in both volunteer studies and clinical case series $[1,2]$, although clinical benefit is uncertain. The beneficial effect of MDAC is purported to be exerted through a gastrointestinal dialysis effect. While it was well tolerated in our patient, we cannot confirm whether it influenced outcome.

Theophylline is a relatively small molecule $(180 \mathrm{Da})$ with a low volume of distribution $(0.5 \mathrm{~L} / \mathrm{kg})$ and low protein binding (56\%). These characteristics make it amenable to extracorporeal elimination. Endogenous clearance of the drug is low (approximately $50 \mathrm{~mL} / \mathrm{min}$ ) and may be even slower following overdose when metabolic pathways are saturated. Numerous reports suggest both haemoperfusion and intermittent haemodialysis enhance theophylline elimination [7-10].

Historically, given the high clearance rates, charcoal haemoperfusion has been recommended as the preferred treatment of theophylline intoxication in toxicology textbooks and 
clinical reports. Intermittent haemodialysis was considered an acceptable therapy if haemoperfusion was unavailable [3, 4]. Recent improvements in haemodialysis technology (e.g. highflux membranes and higher blood flow rates, up to $500 \mathrm{~mL} /$ min) mean older comparisons between both modalities are less relevant.

In our patient, haemodialysis-associated plasma clearance (up to $103 \mathrm{~mL} / \mathrm{min}$ ) was achieved with a blood flow rate of $250 \mathrm{~mL} / \mathrm{min}$; however, higher clearance might be achievable with higher blood flow rates. This clearance rate is lower than that reported for haemoperfusion (around $200 \mathrm{~mL} / \mathrm{min}$ ). However, haemodialysis may have a comparable effect in reducing morbidity and a lower complication rate than haemoperfusion in severe theophylline poisoning $[5,7]$.

Haemoperfusion complications include short charcoal cartridge life expectancy, thrombocytopenia and hypocalcemia. Other disadvantages are the high cost of the cartridges relative to dialysis filters and higher doses of anticoagulation required. Increasing use of high-flux haemodialysis technology has seen a decline in the use of charcoal haemoperfusion, along with reduction in availability of charcoal cartridges and the expertise required to use these [11]. In addition to the removal of toxicants, haemodialysis also corrects acid-base and electrolyte disturbances and volume overload. For these reasons, haemodialysis has become the treatment of choice for most dialysable poisonings [12].

SLED is a prolonged renal replacement therapy using blood and dialysate flow rates between those of haemodialysis and continuous renal replacement therapy. It is also known as "prolonged intermittent renal replacement therapy" or PIRRT. The usual treatment duration is between 6 and $12 \mathrm{~h}$. Like continuous renal replacement therapy, it is available and familiar to ICU staff. In many centres, it does not require the approval of a nephrologist or nephrology unit nursing staff to operate. As a result, there may be less delay in commencing treatment compared to intermittent haemodialysis. However, the literature on the use of SLED in poisoned patients is limited [13-15].

We commenced SLED after our first cycle of haemodialysis when theophylline concentration rebound was noted as it was late at night and dialysis unit nursing staff were not available to restart intermittent haemodialysis. While extraction ratios were lower than with intermittent haemodialysis, apparent elimination half-life was relatively short during the two cycles of SLED and comparable to reports in the literature with intermittent techniques $[5,7,10]$. Clearance was lower during SLED than haemodialysis due to the blood flow rate used $(180 \mathrm{~mL} / \mathrm{min})$. This was a conservative approach adopted by ICU staff using a relatively new treatment modality. For treatments of less than $8 \mathrm{~h}$, blood flow rates of 200-300 $\mathrm{mL}$ are achievable with SLED and might result in further increases in clearance. Intermittent haemodialysis was not recommenced the next day, given the significant fall in serum theophylline concentration and the lack of CVS or CNS toxicity with this.

It is likely ongoing theophylline absorption and administration of MDAC had a confounding effect on the elimination half-life of theophylline in this patient; however, the influence of each was not measurable.

Given the higher estimated clearance rate with intermittent haemodialysis, this technique is still preferable in the initial stages of theophylline toxicity. The aim of extracorporeal therapy should be to facilitate rapid reduction in blood drug concentrations during peak toxicity and, in particular, prevent neurologic toxicity and seizures. At this time, it is uncertain whether SLED is as effective in the acute phase of toxicity.

A limitation of this report is that the conservative blood flow rates used during both haemodialysis and SLED limited the plasma clearance achieved, while the key benefit of haemodialysis is the potentially high flow rates achievable with currently available filters. Future case reports of drug intoxication utilizing SLED as a treatment should attempt to measure dialysate drug recovery to ascertain accurate clearance data.

\section{Conclusion}

At this time, intermittent haemodialysis is the preferable modality to enhance theophylline elimination in cases of severe toxicity. In situations where there may be a delay to the institution of intermittent haemodialysis or where this is unavailable and/or the transfer of an unstable patient to another centre is dangerous or impractical, SLED may be considered as an alternate modality for the treatment of life-threatening intoxication.

Conflict of interest The authors report no conflict of interest.

\section{References}

1. Berlinger WG, Spector R, Goldberg MJ, Johnson GF, Quee CK, Berg MJ (1983) Enhancement of theophylline clearance by oral activated charcoal. Clin Pharmacol Ther 33:351-4

2. True RJ, Berman JM, Mahutte CK (1984) Treatment of theophylline toxicity with oral activated charcoal. Crit Care Med 12:113-4

3. Heath A, Knudsen K (1987) Role of extracorporeal drug removal in acute theophylline poisoning — a review. Med Toxicol 2:294-308

4. Gaudrealt P (1986) Theophylline poisoning, pharmacological considerations and clinical management. Med Toxicol 1:169-91

5. Benowitz NL, Toffelmire EB (1993) The use of hemodialysis and hemoperfusion in the treatment of theophylline intoxication. Semin Dial 6:243-52

6. American Academy of Clinical Toxicology and European Association of Poisons Centres and Clinical Toxicologists (2004) Position paper: whole bowel irrigation. J Toxicol Clin Toxicol 242: 843-85 
7. Shannon MW (1997) Comparative efficacy of haemodialysis and hemoperfusion in severe theophylline intoxication. Acad Emerg Med 4:674-8

8. Woo O, Pond S, Benowitz N, Olson K (1984) Benefit of hemoperfusion in acute theophylline intoxication. Clin Toxicol 22(5):411-24

9. Burgess E, Sargious P (1995) Charcoal hemoperfusion for theophylline overdose: case report and proposal for predicting treatment time. Pharmacotherapy 15:621-4

10. Higgins RM, Hearing S, Goldsmith DJ, Keevil B, Venning MC, Ackrill P (1995) Severe theophylline poisoning: charcoal haemoperfusion or haemodialysis? Postgrad Med J 71:224-6

11. Ghannoum M, Bouchard J, Nolin TD, Ouellet G, Roberts DM (2014) Hemoperfusion for the treatment of poisoning: technology, determinants of poison clearance and application in clinical practice. Semin Dial 27(4):350-61
12. Ouellet G, Bouchard J, Ghannoum M, Decker BS (2014) Available extracorporeal treatments for poisoning: overview and limitations. Semin Dial 27(4):342-9

13. Bailey AR, Sathianathan VJ, Chiew AL, Paterson AD, Chan BS, Arora S (2011) Comparison of intermittent haemodialysis, prolonged intermittent renal replacement therapy and continuous renal replacement haemofiltration for lithium toxicity: a case report. Crit Care Resusc 13:120-2

14. Fiaccadori E, Maggiore U, Parenti E, Greco P, Cabassi A (2008) Sustained low-efficiency dialysis (SLED) for acute lithium intoxication. Nephrol Dial Transplant 5:329-32

15. Lund B, Seifert SA, Mayersohn M (2005) Efficacy of sustained lowefficiency dialysis in the treatment of salicylate toxicity. Nephrol Dial Transplant 20:1483-4 